\title{
Antidiabetic Effect of Salvianolic Acid A on Diabetic Animal Models via AMPK Activation and Mitochondrial Regulation
}

\author{
Guifen Qiang $^{a}$ Xiuying Yanga,b Lili Shic Hengai Zhang ${ }^{a}$ Bainian Chen ${ }^{a}$ \\ Yan Zhao ${ }^{d}$ Mian Zu ${ }^{a}$ Dan Zhou Jing Guo Haiguang Yanga,b Li Zhanga,b \\ Guanhua Du,b \\ anstitute of Materia Medica, Chinese Academy of Medical Sciences and Peking Union Medical \\ College, Beijing, 'Beijing Key Laboratory of Drug Target Identification and Drug Screening, Beijing, \\ 'GeneQuantum Healthcare (Suzhou) Co. Ltd., Suzhou, 'Qingdao Municipal Hospital, Qingdao, China
}

\section{Key Words}

Salvianolic acid A • Diabetes mellitus • Antidiabetic $\bullet$ Mitochondria $\bullet$ AMPK $・$ ATP $\bullet$ Mitochondrial membrane potential

\begin{abstract}
Background/Aims: Diabetes mellitus (DM) characterized by hyperglycemia contributes to macrovascular and microvascular complications. Salvianolic acid A (SalA) is a polyphenolic compound isolated from the root of Salvia miltiorrhiza Bunge, which is a traditional Chinese medicine widely used to treat cardiovascular diseases. However, little is known about its antidiabetic effect. Our study aimed to investigate the in vivo and in vitro antidiabetic effect of SalA and the underlying mechanisms. Methods: Alloxan-induced type 1 diabetic mice and high-fat diet (HFD) and low-dose streptozotocin (STZ)-induced type 2 diabetic rats received SalA treatment. Blood glucose, oral glucose tolerance test (OGTT), 24-h food and water intake were monitored. In vitro, glucose consumption and uptake were measured in HepG2 cells and L6 myotubes. Mitochondrial function was detected in hepatic and skeletal muscle mitochondria. AMP-activated protein kinase (AMPK) and Akt were analyzed by western blot Results: In both type 1 and type 2 diabetic animals, SalA lowered fasting blood glucose (FBG) and fed blood glucose in dose-dependent manner, as well as reduced 24-h food and water intake. In vitro, SalA caused dose-dependent increase in glucose consumption and enhanced glucose uptake. SalA significantly increased ATP production from $10 \mathrm{~min}$ to $12 \mathrm{~h}$ in HepG2 cells and L6 myotubes. Interestingly, SalA decreased mitochondrial membrane potential (MMP) in HepG2 cells. Furthermore, SalA improved hepatic and skeletal muscle mitochondrial function, increased ATP production, and concurrently decreased MMP. In particularly, SalA activated AMPK phosphorylation through $\mathrm{Ca}^{2+} /$ calmodulin-dependent protein kinase kinase $\beta$ (CaMKK $\beta$ )/AMPK signaling pathway, independent of liver kinase 1 (LKB1)/AMPK pathway.

G. Qiang and X. Yang contributed equally to this work.
\end{abstract}

Professor Li Zhang

and Professor Guanhua Du

KARGER 125
National Center for Pharmaceutical Screening Institute of Materia Medica, Chinese Academy of Medical Sciences and Peking Union Medical College, Beijing 100050 (PR China)

E-Mail zhangli@imm.ac.cn; E-Mail dugh@imm.ac.cn 


\section{Cellular Physiology Cell Physiol Biochem 2015;36:395-408

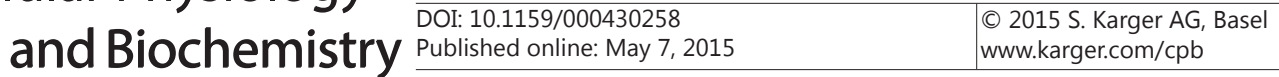 \\ Qiang et al:: Antidiabetic Effect of Salvianolic Acid A via Mitochondrial Regulation}

However, SalA didn't show any effect on insulin secretagogue and activation of PI3K/Akt signaling pathway. Conclusion: SalA exhibits the antidiabetic effects in diabetic animal models through improving mitochondrial function, increasing ATP production, and decreasing MMP via CaMKKß/AMPK signaling pathway.

Copyright (C) 2015 S. Karger AG, Basel

\section{Introduction}

Diabetes mellitus (DM) and its complications are running rampantly in the world, which is associated with increased morbidity and mortality. As hyperglycemia is a fundamental abnormality contributing to macrovascular and microvascular complications, glucose-lowering strategy is very important in the treatment of type 2 diabetes to reduce the risk for diabetes complications [1,2]. Since oral antidiabetic agents were available in clinic 60 years ago, more attentions have been focused on hypoglycemic efficacy. However, more and more emerging drug safety issues have gained extensive concerns [3]. The use of metformin is contraindicated in patients with renal dysfunction [4]. In addition, food and drug administration (FDA) issued a new warning about the side effects of thiazolidinediones (TZDs), such as weight gain, edema, heart and liver failure. Therefore, development of new antidiabetic agents with greater safety and efficacy is of great necessity. Recently, mitochondrial function and AMP-activated protein kinase (AMPK) are known to be closely involved in glucose metabolism, which have been regarded as the potential therapeutic targets for diabetes and diabetes complications.

Medicinal plants have been identified and widely used for the treatment of various diseases in developing countries [5, 6]. Plants have the ability to synthesize a wide variety of chemical compounds, which give a great opportunity for the discovery of antidiabetic agents. Salvianolic acid is a polyphenolic compound isolated from the root of Salvia Miltiorrhiza Bunge, which is a traditional Chinese medicine and widely used in the Asian countries for the treatment of cardiovascular and cerebrovascular diseases with wellknown safety [7]. Salvianolic acid A (SalA)(2R)-3-(3,4-Dihydroxyphenyl)-2-[(E)-3-[2-[(E)-2(3,4-dihydroxyphenyl) ethenyl]-3,4-dihydroxyphenyl]prop-2-enoyl] oxypropanoic acid) has been reported to have extensive pharmacological effects including antioxidant, anti-platelet aggregation, anti-cerebral and myocardial ischemia [8-12]. Salvianolic acid B, as one of salvianolic acid, was found to protect against high-fat diet-induced obesity recently [13]. In our previous studies, we have demonstrated that SalA ameliorated diabetes complications, such as vascular disease and peripheral neuropathy [14-16].

Here, our study reported that SalA lowers blood glucose, improves glucose tolerance, as well as reduces food and water intakes. Further studies demonstrated that SalA regulates glucose metabolism by increasing ATP production, decreasing mitochondrial membrane potential (MMP) and improving mitochondrial function via $\mathrm{Ca}^{2+} /$ calmodulin-dependent protein kinase kinase $\beta$ (CaMKK $\beta$ )/AMPK signaling pathway, not phosphatidyl inositol 3' kinase (PI3K)/Akt signaling pathway. All these results indicated that SalA might be a novel and promising drug candidate for diabetes treatment.

\section{Materials and Methods}

Chemicals

Compounds were purchased from the following sources: Metformin was from Bristol-Myers Squibb Co., China. SalA is a water-soluble component from Salvia Miltiorrhiza Bunge, which was isolated by Beijing Collab Co., China as a lyophilized powder, with a purity of over $94 \%$ by HPLC analysis.

Experimental Animals

Male ICR mice (18-20 g, 8 weeks old) and male Wistar rats (180-200 g, 8 weeks old) were purchased from Vital River Laboratory Animal Technology Co. Ltd (Beijing, China). The animals were housed under standard environmental conditions $\left(22-25^{\circ} \mathrm{C}\right.$, humidity $60-70 \%, 12 \mathrm{~h}$ light/dark cycles). This study was 


\section{Cellular Physiology Cell Physiol Biochem 2015;36:395-408 \begin{tabular}{l|l} 
DOI: 10.1159/000430258 & $\begin{array}{l}\text { C 2015 S. Karger AG, Basel } \\
\text { www.karger.com/cpb }\end{array}$ \\
\hline
\end{tabular} Qiang et al.: Antidiabetic Effect of Salvianolic Acid A via Mitochondrial Regulation}

carried out in accordance with the Guide for the Animal Care \& Welfare Committee of Institute of Materia Medica, Chinese Academy of Medical Sciences.

\section{Type 1 diabetic mice and treatments}

After fasted for $16 \mathrm{~h}$, male ICR mice were injected intravenously with $63 \mathrm{mg} / \mathrm{kg}$ alloxan (Sigma, USA). After $72 \mathrm{~h}$, mice with fasting blood glucose (FBG) higher than $10 \mathrm{mM}$ were considered as diabetic mice. The diabetic mice were orally administered with SalA $(0.4,1.3 \mathrm{mg} / \mathrm{kg})$, metformin $(200 \mathrm{mg} / \mathrm{kg})$, or vehicle (DM group) once a day for 15 days. Age-matched mice were treated with vehicle as normal control (NC) group.

\section{Type 2 diabetic Rats and treatments}

Male Wistar rats were randomly divided into NC group and diabetic group. NC rats were fed with standard diet ( $41.47 \%$ carbohydrate, $14.42 \%$ fat, $21.06 \%$ protein), while rats in diabetic group were fed with high-fat and high-sucrose diet (standard rat diet supplemented with $10 \%$ sucrose, $10 \%$ lard, $2 \%$ cholesterol, and $0.2 \%$ cholic acid) for 4 weeks, and then injected intraperitoneally with streptozotocin (STZ, $30 \mathrm{mg} / \mathrm{kg}$, Sigma, USA) [17-19]. Seven days after STZ injection, the animals with FBG higher than $10 \mathrm{mM}$ were considered as diabetic rats. The diabetic rats were randomly divided into 4 groups: untreated diabetic group (DM group), metformin-treated diabetic group (Metformin $150 \mathrm{mg} / \mathrm{kg}$ ) and SalA-treated diabetic group (SalA 1 and $3 \mathrm{mg} / \mathrm{kg}$ ). All diabetic rats were fed with a high-fat diet (standard rat diet supplemented with $10 \%$ lard, $2 \%$ cholesterol, $0.2 \%$ cholic acid), while NC rats were fed with a standard diet for 4 weeks.

\section{Measurements of blood glucose, glycosylated hemoglobin and oral glucose tolerance test}

Blood glucose and glycosylated hemoglobin (GHB) were tested according to manufacturer's instruction (Beijing Biosino Co, China). To determine FBG, animals were fasted for $4 \mathrm{~h}$. Fed blood glucose samples were collected without fasting and free to feed. Oral glucose tolerance test (OGTT) was performed after the animals were fasted for $4 \mathrm{~h}$ followed by glucose solution $(2.0 \mathrm{~g} / \mathrm{kg})$ by oral gavage. The blood samples were collected at $0,30,60,120$ min after glucose loading.

\section{Cell Culture}

L6 cells (rat myoblast cell line) were maintained in Minimal Essential Medium (MEM) supplemented with $10 \% \mathrm{FBS}$ at $37{ }^{\circ} \mathrm{C}, 5 \% \mathrm{CO}_{2}$. To induce cells differentiation, medium was switched to MEM with $2 \%$ FBS for 7 days after complete confluence. The medium was changed every two days. HepG2 cells (human hepatoma cell line), MIN6 cells (mouse insulinoma cell line) and HeLa cells (human cervical cancer cell line) were from National Platform of Experimental Cell Resources for Sci-Tech, Chinese Academy of Medical Sciences. They were cultured in DMEM (5.5 or $25.5 \mathrm{mmol} / \mathrm{L}$ ) supplemented with $10 \% \mathrm{FBS}$ at $37{ }^{\circ} \mathrm{C}, 5 \% \mathrm{CO}_{2}$.

Glucose consumption and glucose uptake

Glucose consumption was conducted as described previously [20]. In brief, HepG2 cells or differentiated L6 myotubes in 96-well plate were treated with different concentrations of SalA $\left(10^{-8}-10^{-6}\right.$ $\mathrm{M})$ and insulin $\left(3 \times 10^{-8} \mathrm{M}\right)$ in DMEM or MEM medium (5.5 mM glucose) at $37^{\circ} \mathrm{C}, 5 \% \mathrm{CO}_{2}$. After treatment for $24 \mathrm{~h}$, the supernatant was taken for glucose assay.

The glucose uptake was performed with the radioactive substances $\left[{ }^{3} \mathrm{H}\right]$-2-deoxy-D-glucose (Perkin Elmer, USA) as described previously [21]. In brief, differentiated L6 myotubes in 24-well plate were starved with serum-free MEM for $2 \mathrm{~h}$, and pretreated with cytochalasin B (20 $\mu \mathrm{M}$, Serva, German) for 5 min as non-specific uptake. The cells were then washed and incubated with $400 \mu \mathrm{l}$ of Krebs-Ringer phosphateHEPES buffer (131.2 mmol/L NaCl, $4.71 \mathrm{mmol} / \mathrm{L}$ potassium chloride, $2.47 \mathrm{mmol} / \mathrm{L} \mathrm{CaCl}, 1.24 \mathrm{mmol} / \mathrm{L}$ magnesium sulfate, $2.48 \mathrm{mmol} / \mathrm{L}$ monosodium phosphate, $10 \mathrm{mmol} / \mathrm{L} \mathrm{HEPES}$, and 0.5\% BSA [pH 7.45]) containing different concentrations of SalA $\left(10^{-8}-10^{-6} \mathrm{M}\right)$ or insulin $\left(10^{-7} \mathrm{M}\right.$, Sigma, USA) for 30 min at 37 ${ }^{\circ} \mathrm{C}$. After adding $100 \mu \mathrm{l}$ of 2-deoxy-D-glucose $\left(50 \mu \mathrm{M}\right.$, Sigma, USA) with $\left[{ }^{3} \mathrm{H}\right]$-2DG (0.2 $\mu \mathrm{Ci} /$ well) for $10 \mathrm{~min}$, uptake was terminated by washing three times with ice-cold Krebs-Ringer phosphate-HEPES buffer and solubilized in $0.2 \mathrm{~mol} / \mathrm{L}$ sodium hydroxide $(\mathrm{NaOH})$. The radioactivity was measured by scintillation counter (Perkin Elmer, USA).

Measurement of ATP production

Intracellular ATP level was determined by CellTiter-Glo ${ }^{\circledR}$ kit (Promega, USA) according to manufacturer's instruction. Briefly, HepG2 cells or L6 myotubes were treated with different concentrations 


\section{Cellular Physiology Cell Physiol Biochem 2015;36:395-408 \\ \begin{tabular}{l|l|l}
\cline { 2 - 2 } DOI: 10.1159/000430258 & (c) 2015 S. Karger AG, Basel
\end{tabular}

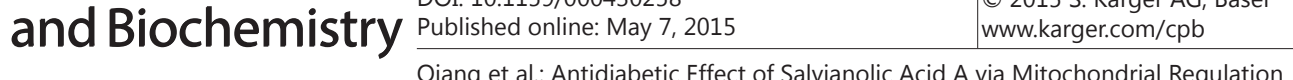

of SalA $\left(10^{-9}-10^{-6} \mathrm{M}\right)$ for $10 \mathrm{~min}$ to $12 \mathrm{~h}$. Then, $100 \mu \mathrm{l} \mathrm{CellTiter-Glo}{ }^{\mathrm{TM}}$ reagent was added and mixed thoroughly. The luminescence was recorded by Spectra Max M5 microplate reader (Molecular Devices, USA).

\section{Measurement of mitochondrial function}

Isolation of mitochondria. The isolation of mitochondria was performed as previously described [22]. The liver and skeletal muscle tissues were quickly removed after the animals were sacrificed and finely minced in ice-cold isolation buffer ( $0.25 \mathrm{M}$ sucrose, $10 \mathrm{mM}$ Tris-HCl, $1 \mathrm{mM}$ EDTA, and $1 \mathrm{~g} / \mathrm{L} \mathrm{BSA}$, pH7.4). The tissue homogenates $(10 \%, \mathrm{w} / \mathrm{v})$ were generated in glass homogenizer. After removing cell debris by centrifugation at $1000 \mathrm{~g}$ for $10 \mathrm{~min}$, the supernatant was subjected to further centrifugation at 10,000 $\mathrm{g}$ for $10 \mathrm{~min}$ to harvest mitochondria with final concentration of $20-25 \mathrm{mg} / \mathrm{ml}$.

\section{Measurement of mitochondrial respiratory activity}

Oxygen consumption was measured by Clark type oxygen electrodes (Strathkelvin Instruments, British) at $25^{\circ} \mathrm{C}$. Mitochondrial respiration was detected by adding $1 \mathrm{mg} / \mathrm{ml}$ hepatic or skeletal muscle mitochondria in $1 \mathrm{ml}$ of respiration medium $(225 \mathrm{mM}$ sucrose, $5 \mathrm{mM}$ potassium phosphate buffer, $\mathrm{pH}$ 7.4, 10 $\mathrm{mM}$ Tris- $\mathrm{HCl}, 10 \mathrm{mM} \mathrm{KCl}, 0.2 \mathrm{mM}$ EDTA and $100 \mu \mathrm{g} / \mathrm{L} \mathrm{BSA}$ ). The hepatic and skeletal muscle mitochondria were incubated with different concentrations of SalA $\left(10^{-9}-10^{-6} \mathrm{M}\right)$ at $25{ }^{\circ} \mathrm{C}$ for $10 \mathrm{~min}$. Mitochondrial respiration was initiated by adding complex I substrate ( $10 \mathrm{mM} \mathrm{L-glutamate} \mathrm{plus} 5 \mathrm{mM}$ L-malate), and then adding ADP to a final concentration of $250 \mu \mathrm{M}$. State 3 respiration is oxygen consumption in the presence of ADP, while State 4 respiration is consumption of oxygen after ADP depletion. Respiration control ratio (RCR) is the ratio of State 3 to State 4 respiration, and is used as an indicator of mitochondrial respiration activity [23]. The ADP/O ratio is calculated to be the ratio of ADP concentration to consumption of oxygen during State 3 respiration. Oxidative phosphorylation rate (OPR) is obtained from the calculation of State 3 respiration rate and $\mathrm{ADP} / 0$ ratio.

\section{Measurement of mitochondrial ATP production}

The mitochondria were incubated with different concentrations of SalA $\left(10^{-9}-10^{-6} \mathrm{M}\right)$ at $25^{\circ} \mathrm{C}$ for 10 min, followed by adding $10 \mu \mathrm{l}$ of $2 \mathrm{M} \mathrm{L}$-glutamate plus $0.8 \mathrm{M} \mathrm{L}$-malate, and $15 \mu \mathrm{l}$ of $0.4 \mathrm{M}$ ADP for another $5 \mathrm{~min}$. The luminescence were detected by adding $100 \mu \mathrm{l}$ CellTiter-Glo® reagent (Promega, USA) and recorded by Spectra Max M5 microplate reader (Molecular Devices, USA).

\section{Measurement of mitochondrial membrane potential}

Mitochondrial membrane potential $(\Delta \psi \mathrm{m})$ was measured with fluorescent dye Rhodamine 123 described previously $[24,25]$. In brief, $50 \mu \mathrm{l}$ of mitochondria $(0.5 \mathrm{mg} / \mathrm{ml})$ were added into $150 \mu \mathrm{l}$ buffer ( $150 \mathrm{mM}$ sucrose, $5 \mathrm{mM} \mathrm{MgCl} \cdot 6 \mathrm{H}_{2} \mathrm{O}, 5 \mathrm{mM}$ succinate, $5 \mathrm{mM} \mathrm{KH}_{2} \mathrm{PO}_{4}, 20 \mathrm{mM}$ HEPES, $\mathrm{pH}$ 7.4), followed by adding $10 \mu \mathrm{M}$ of Rhodanmine 123 (Sigma, USA) after treatment with SalA $\left(10^{-9}-10^{-6} \mathrm{M}\right.$ ) for $30 \mathrm{~min}$. The fluorescence intensity (Ex $488 \mathrm{~nm} / \mathrm{Em} 535 \mathrm{~nm}$ ) was recorded. To detect the MMP level in cultured cells, HepG2 cells were incubated with $10 \mu \mathrm{M}$ of Rhodanmine 123 at $37^{\circ} \mathrm{C}$ for 10 min after treatment with SalA $\left(10^{-9}-10^{-6} \mathrm{M}\right)$ for $30 \mathrm{~min}$. After washing with PBS three times, the confocal images were taken and intensities (Ex $488 \mathrm{~nm} / \mathrm{Em} 535 \mathrm{~nm}$ ) were measured. MMP was calculated with the Nernst equation $\left(\Delta \Psi_{\mathrm{m}}(\mathrm{mV})=-59\right.$ $\log [$ Rh123]in/[Rh123]out).

\section{Insulin release}

MIN6 cells were plated into 24-well plate and treated with different concentrations of SalA $\left(10^{-9}\right.$ $10^{-6} \mathrm{M}$ ) for $24 \mathrm{~h}$. Insulin content in the supernatant was determined by radioimmunoassay (Beijing North Institute of Biological Technology, Beijing, China).

The cell viability was measured by MTT assay as previously described [26]. Briefly, after treatment with different concentrations of SalA $\left(10^{-9}-10^{-6} \mathrm{M}\right)$ for $24 \mathrm{~h}$, MTT $(0.5 \mathrm{mg} / \mathrm{ml})$ was added into cells and incubated at $37^{\circ} \mathrm{C}$ for $4 \mathrm{~h}$. Then the supernatant was discarded and DMSO was added. The OD value at 570 nm was recorded by Spectra Max M5 microplate reader (Molecular Devices, USA).

Western blotting

The drug-stimulated cells were lysed in RIPA buffer supplemented with complete protease inhibitor cocktail (Biochem, PA, USA). Equal amounts of protein were subjected to SDS-PAGE and immunoblotted 


\section{Cellular Physiology Cell Physiol Biochem 2015;36:395-408 \\ \begin{tabular}{l|l} 
DOI: 10.1159/000430258 & \\
and Biochemistry Published online: May 7, 2015 & $\begin{array}{l}\text { O 2015 S. Karger AG, Basel } \\
\text { www.karger.com/cpb }\end{array}$
\end{tabular}}

with antibodies specific for total Akt, phospho-Akt (Ser473), total AMPK, phospho-AMPK-a (Thr172) and GAPDH (Cell Signaling Technology, MA, USA).

\section{Statistical analysis}

All data are expressed as mean \pm standard error (S.E.M.) and analyzed using statistical package SPSS 13.0. ANOVA followed by Dunnett's multiple comparison test was used to determine significant differences, with $P<0.05$ as statistically significant.

\section{Results}

Metabolic consequences of SalA in diabetic animal models

Polydipsia, polyphagia, polyuria are characteristic of diabetes, which can be improved by hypoglycemic agent treatment. Improvement of blood glucose is usually concomitant with the reduction of food and water intake. In type 1 diabetic mice, 24-h food and water intake were reduced after 7-day SalA treatment, and markedly reduced after 14-day treatment, stronger than metformin (Fig. 1A, 1B). As shown in Fig. 1C, 14-days treatment of SalA (0.4, $1.3 \mathrm{mg} / \mathrm{kg}$ ) exhibited mild hypoglycemic effect on FBG with about $16 \%$ decrease compared with DM group, but without significant difference. Meanwhile, SalA significantly lowered fed blood glucose in a dose-dependent manner, with a little stronger effect than metformin (Fig. 1D). In OGTT, compared with DM group, SalA lowered the blood glucose after glucose

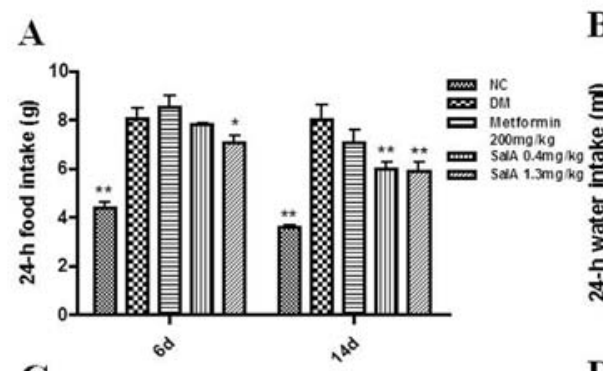

C

B

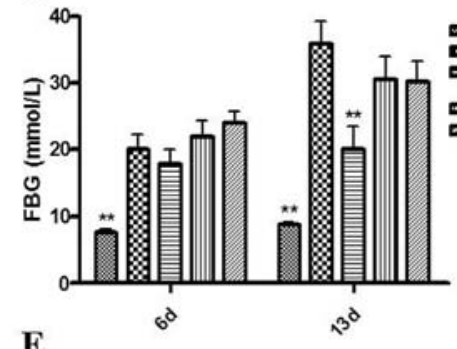

D

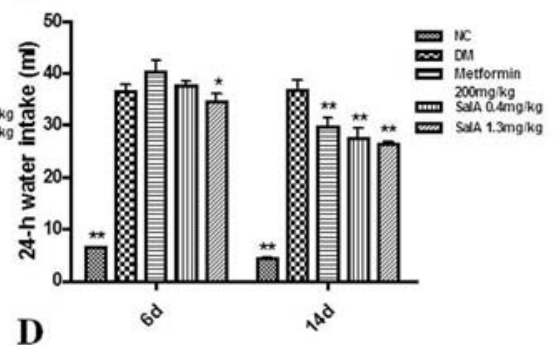

$\mathbf{E}$
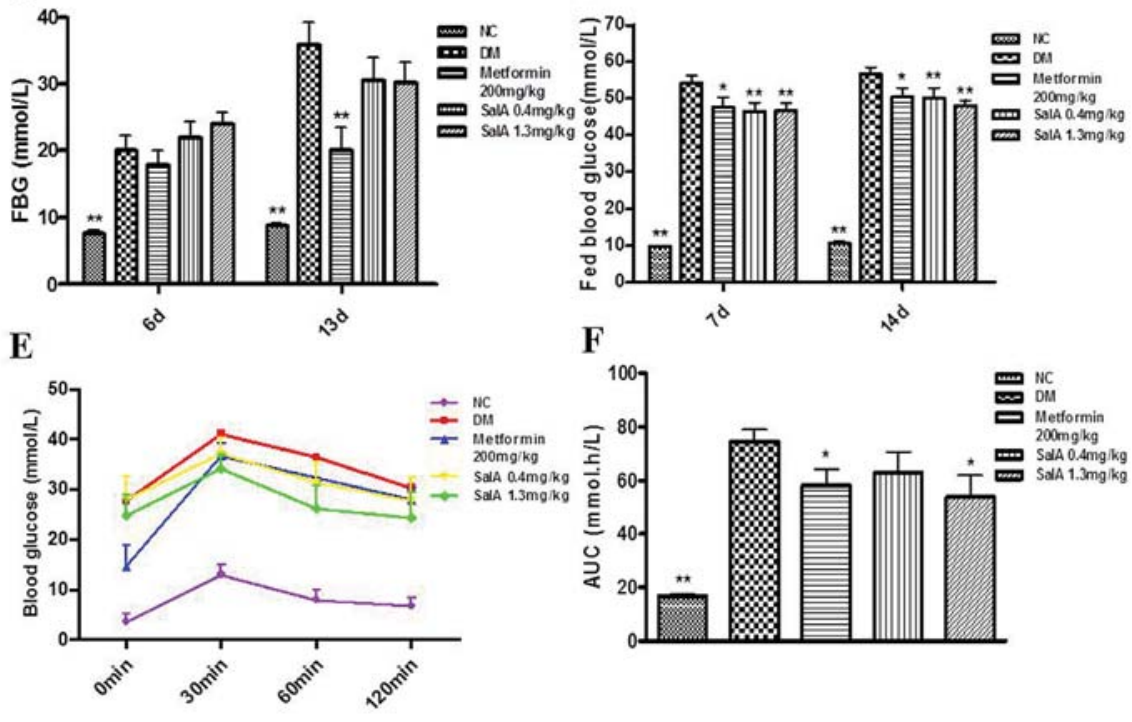

F

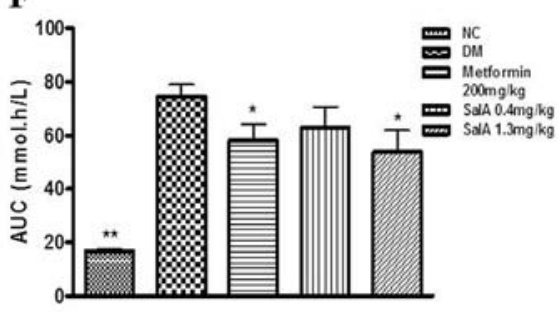

Fig. 1. Antidiabetic effect of SalA in type 1 diabetic mice. (A, B) 24-h food and water intake in untreated type 1 diabetic mice or mice treated with metformin or SalA for the indicated time points. (C, D) Fasting and fed blood glucose in untreated type 1 diabetic mice or mice treated with metformin or SalA for the indicated time points. (E, F) Effects of treatment on OGTT and AUC in type 1 diabetic mice for 15 days. Results are represented as mean \pm S.E.M. $(n=10-12) .{ }^{*} P<0.05,{ }^{* *} P<0.01$ vs. DM group. 


\section{Cellular Physiology Cell Physiol Biochem 2015;36:395-408 \begin{tabular}{c|c|}
\hline DOI: 10.1159/000430258 & O 2015 S. Karger AG, Basel
\end{tabular} \begin{tabular}{l|l} 
and Biochemistry Published online: May 7, 2015 & www.karger.com/cpb \\
\hline
\end{tabular}}

A $\quad$ B
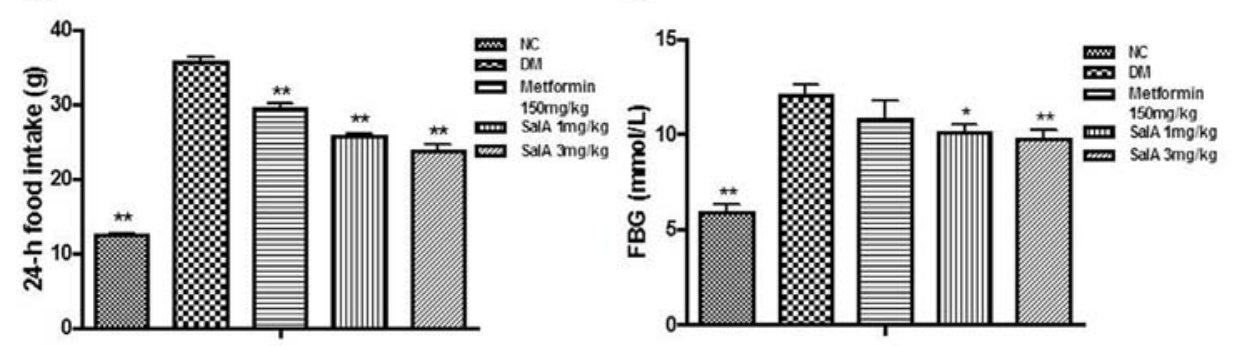

C

D
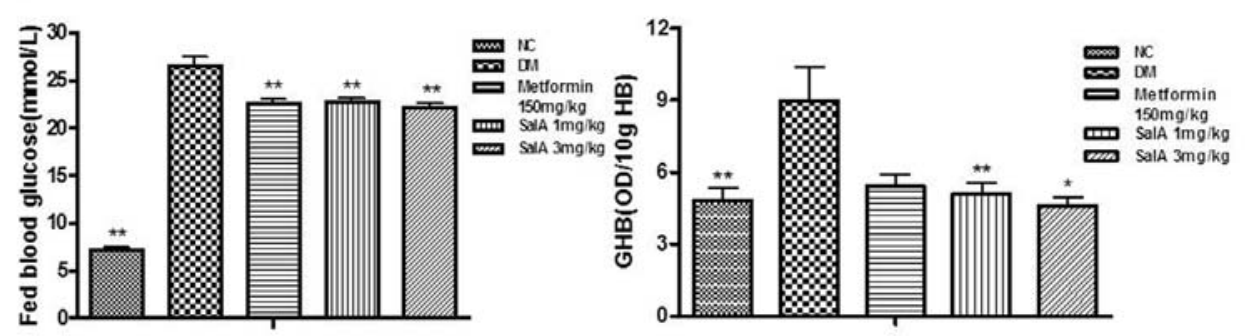

Fig. 2. Antidiabetic effect of SalA in type 2 diabetic rats. (A) Effect of 4-week treatment of metformin or SalA on 24-h food intake. (B, C, D) Fasting blood glucose, fed blood glucose, and glycosylated hemoglobin in untreated type 2 diabetic rats or rats treated with metformin or SalA for 4 weeks. Results are represented as mean \pm S.E.M. $(n=10-12) .{ }^{*} P<0.05,{ }^{* *} P<0.01$ vs. DM group.

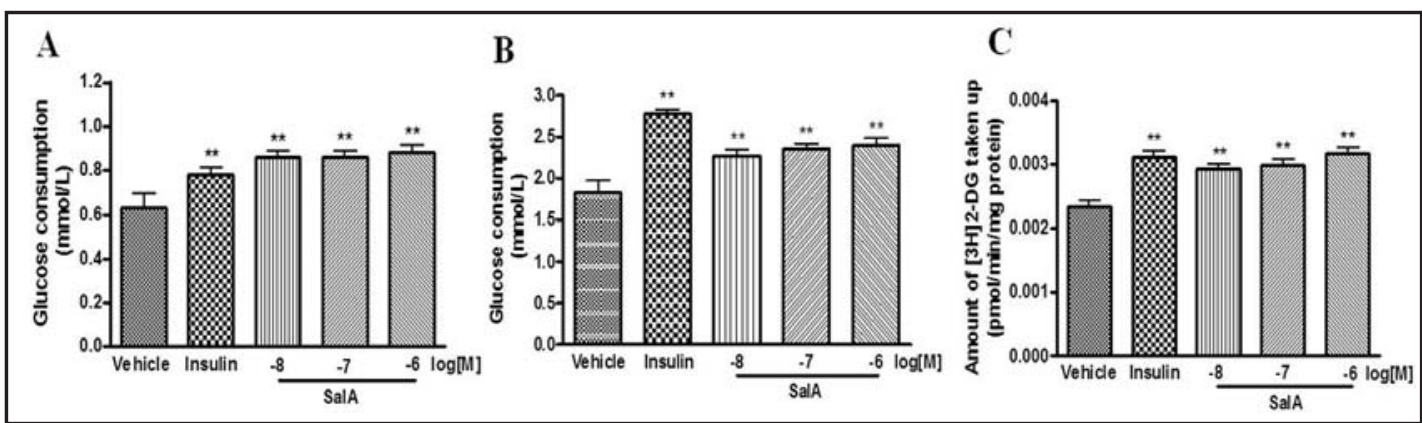

Fig. 3. SalA increased glucose consumption and enhanced cellular glucose uptake. (A, B) SalA increased glucose consumption. After (A) HepG2 cells or (B) L6 myotubes in 96-well plate were treated with different concentrations of SalA $\left(10^{-8}-10^{-6} \mathrm{M}\right)$ and insulin $\left(3 \times 10^{-8} \mathrm{M}\right)$ for $24 \mathrm{~h}$, the supernatant was taken for glucose assay. (C) SalA stimulated glucose uptake. Differentiated L6 myotubes in 24-well plate were incubated in serum-free MEM for $2 \mathrm{~h}$, and then pretreated with $20 \mu \mathrm{M}$ cytochalasin B for $5 \mathrm{~min}$ as non-specific uptake. The cells were incubated with SalA $\left(10^{-8}-10^{-6} \mathrm{M}\right)$ or insulin $\left(10^{-7} \mathrm{M}\right)$ at the indicated concentrations for 30 min. Glucose uptake was performed after adding [ $\left.{ }^{3} \mathrm{H}\right]-2 \mathrm{DG}(0.2 \mu \mathrm{Ci} /$ well $)$ and 2-deoxy-D-glucose $(50 \mu \mathrm{M})$ for $10 \mathrm{~min}$. Results are represented as mean \pm S.E.M. from three separate experiments. ${ }^{*} P<0.05,{ }^{* *} P<0.01$ vs. vehicle group.

loading and reduced the area under curve (AUC), indicating that SalA improved the glucose tolerance (Fig. 1E, 1F).

We also confirmed the antidiabetic effect of SalA in type 2 diabetic rat model. Compared with DM group, 24-h food intake was markedly reduced by 4-week administration of SalA (1, $3 \mathrm{mg} / \mathrm{kg}$ ) with significant difference (Fig. 2A). SalA treatment significantly lowered FBG and fed blood glucose in dose-dependent manner, similar to metformin (Fig. 2B, 2C). Glycosylated hemoglobin in the blood reflects the average blood glucose levels over the preceding 2-3 months. Compared with DM group, SalA markedly reduced the glycosylated hemoglobin, which further confirmed the hypoglycemic effects of SalA (Fig. 2D). 


\section{Cellular Physiology Cell Physiol Biochem 2015;36:395-408 \begin{tabular}{l|l|}
\hline DOI: 10.1159/000430258 & O 2015 S. Karger AG, Basel
\end{tabular}

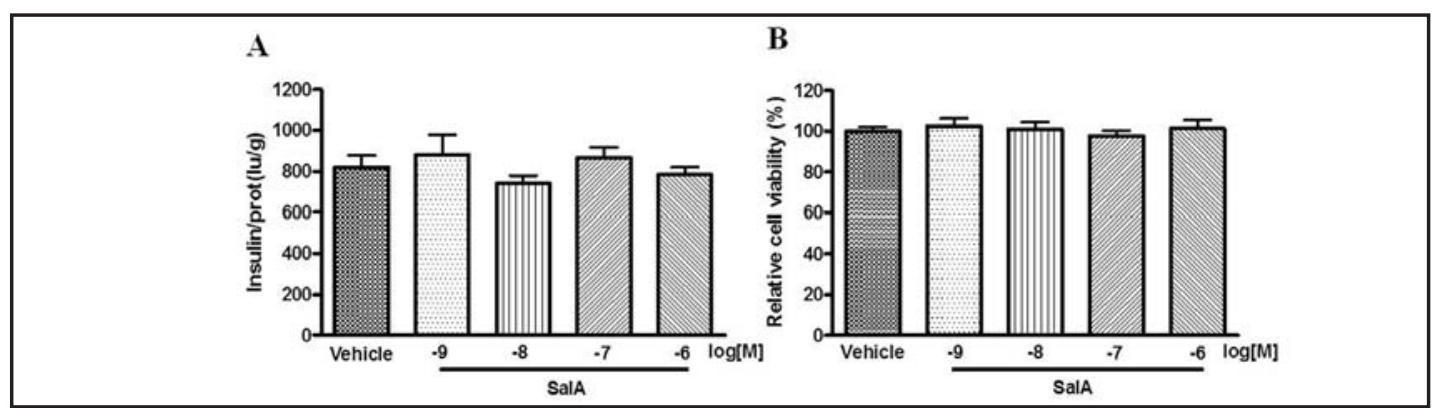

Fig. 4. SalA did not stimulate insulin release. (A) SalA did not stimulate insulin release in MIN6 cells. After MIN6 cells were treated with different concentrations of SalA $\left(10^{-9}-10^{-6} \mathrm{M}\right)$ for $24 \mathrm{~h}$, the supernatant was then taken to determine insulin concentration. (B) SalA did not affect the cell viability of MIN6 cells. Cell viability was measured by MTT assay. Results are represented as mean \pm S.E.M. $(n=6) .{ }^{*} P<0.05,{ }^{* *} P<0.01$ vs. vehicle group.

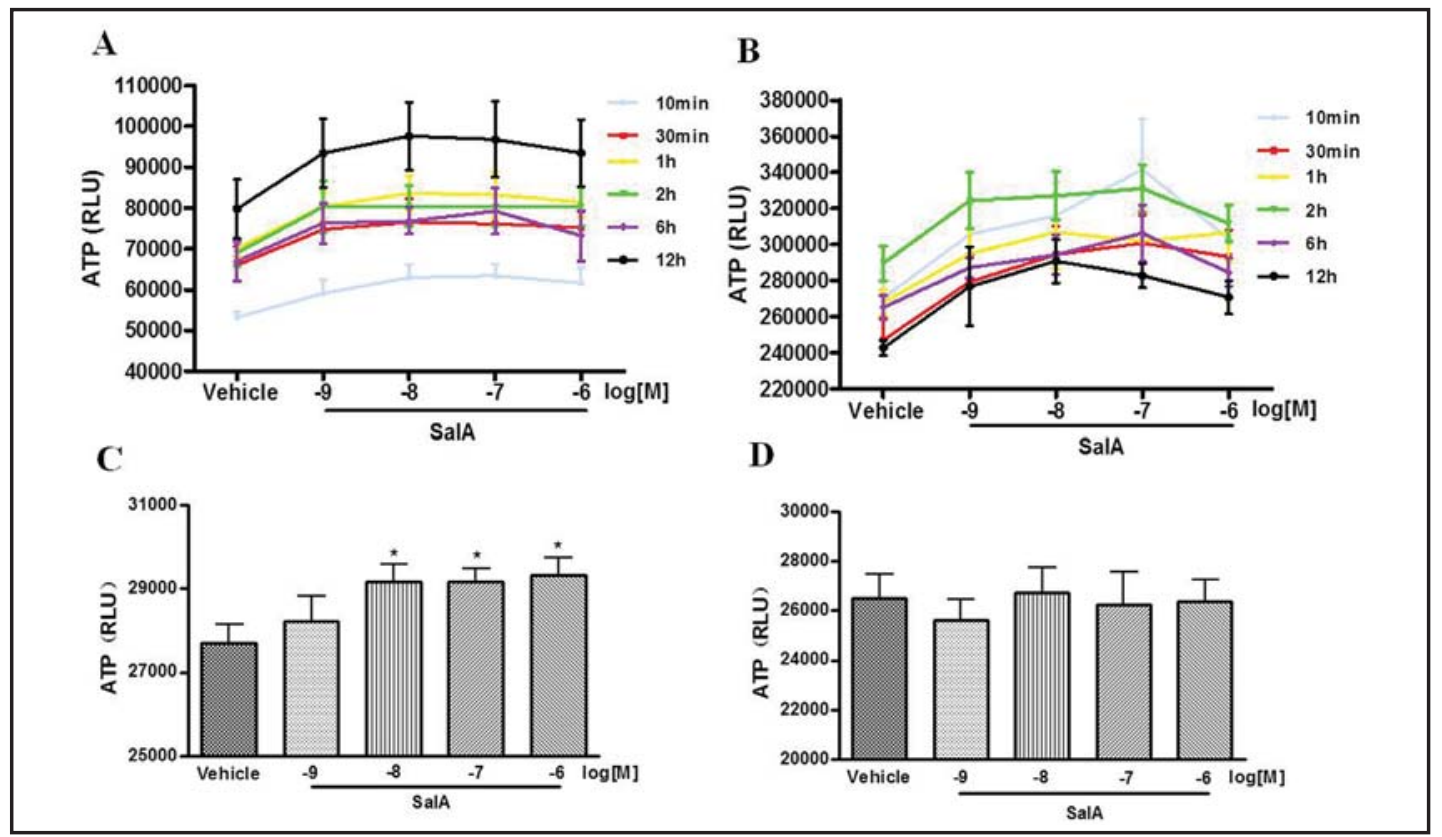

Fig. 5. SalA increased ATP production. After (A) HepG2 cells and (B) differentiated L6 myotubes were treated with SalA $\left(10^{-9}-10^{-6} \mathrm{M}\right)$, ATP was detected from $10 \mathrm{~min}$ to $12 \mathrm{~h}$. After (C) hepatic and (D) skeletal muscle mitochondria were treated with SalA $\left(10^{-9}-10^{-6} \mathrm{M}\right)$ for $10 \mathrm{~min}$ followed by respiratory substrate I (L-glutamate, L-malate) and ADP for $5 \mathrm{~min}$, CellTiter-Glo reagent $100 \mu \mathrm{l}$ was added and luminescence was detected 10 min later. Results are represented as mean \pm S.E.M. $(n=6) .{ }^{*} P<0.05,{ }^{* *} P<0.01$ vs. vehicle group.

Collectively, SalA lowered fasting and fed blood glucose with the reduction of 24-h food and water intake, exhibiting antidiabetic effect in both type 1 and type 2 diabetic animal models.

SalA increased glucose consumption and enhanced glucose uptake

Since SalA displayed the antidiabetic effect in vivo, we then investigated the glucose metabolic activity of SalA in vitro to unveil the mechanisms. To this end, we examined the effect of SalA on glucose consumption and uptake. As shown in Fig. 3A and 3B, both HepG2 cells and L6 myotubes exhibited the elevated glucose consumption in a dose-dependent manner under SalA treatment. In addition, glucose uptake was enhanced in L6 myotubes treated by SalA. $10^{-6} \mathrm{M}$ SalA had the strongest effect, similar to $10^{-7} \mathrm{M}$ insulin (36\% increase, Fig. 3C). It suggested that SalA can increase glucose consumption and enhance glucose uptake in vitro. 


\section{Cellular Physiology Cell Physiol Biochem 2015;36:395-408

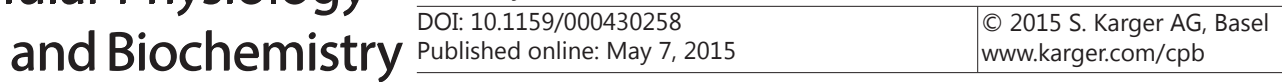 \\ Qiang et al:: Antidiabetic Effect of Salvianolic Acid A via Mitochondrial Regulation}

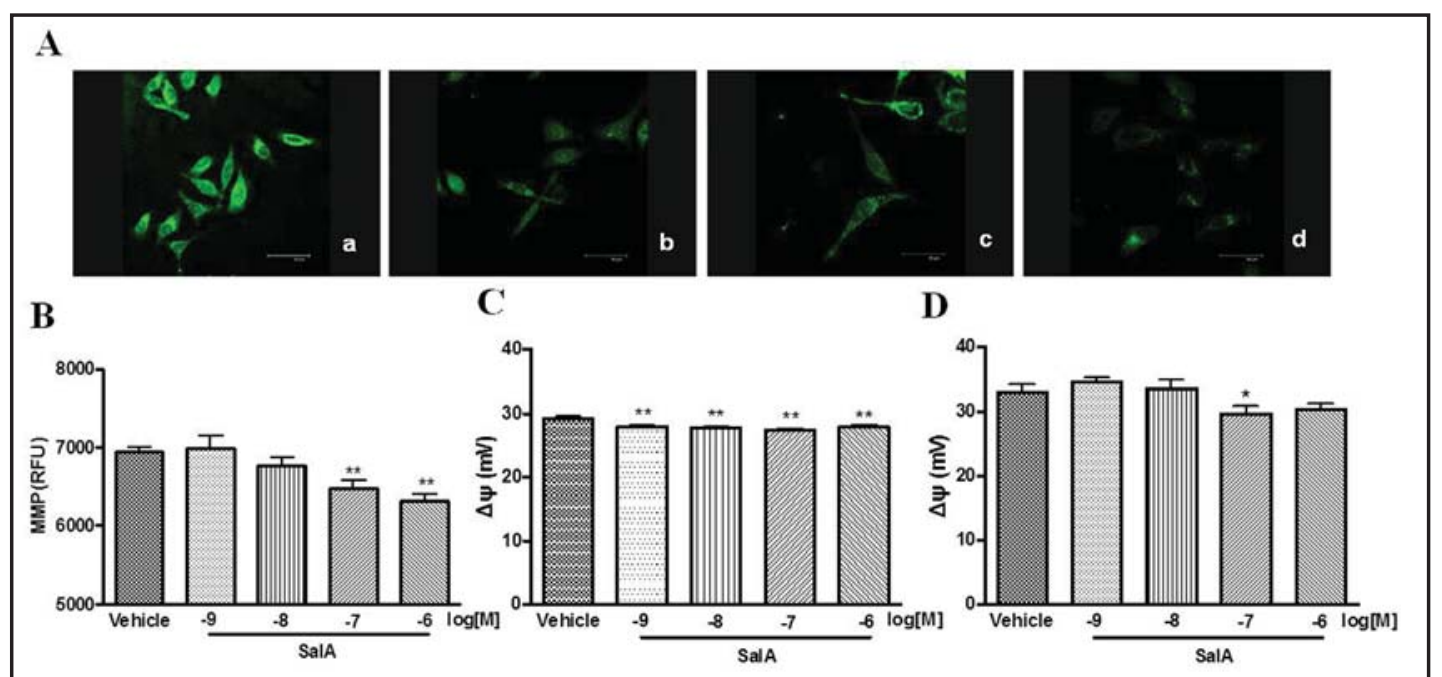

Fig. 6. SalA decreased mitochondrial membrane potential. After HepG2 cells were incubated with SalA $\left(10^{-9}-10^{-6} \mathrm{M}\right)$ for $30 \mathrm{~min}, 10 \mu \mathrm{M}$ of Rhodanmine 123 was added and incubated for $10 \mathrm{~min}$. (A) Confocal images (a: Vehicle, b: SalA $10^{-8} \mathrm{M}$, c: SalA $10^{-7} \mathrm{M}$, d: SalA $10^{-6} \mathrm{M}$ ) were taken and (B) fluorescence intensity were measured. After mitochondria were incubated with SalA $\left(10^{-9}-10^{-6} \mathrm{M}\right)$ for $30 \mathrm{~min}, 10 \mu \mathrm{M}$ of Rhodanmine 123 was added and incubated for $10 \mathrm{~min}$. The fluorescence intensity in (C) hepatic mitochondria and (D) skeletal muscle mitochondria was recorded. Results are represented as mean \pm S.E.M. $(n=6) .{ }^{*} P<0.05$, ${ }^{* *} P<0.01$ vs. vehicle group.

\section{SalA did not stimulate insulin release in MIN6 cells}

To clarify whether SalA lower the blood glucose through stimulating insulin release like insulin, MIN6 cells were treated with SalA at different concentrations for $24 \mathrm{~h}$. Both of insulin release and cellular toxicity revealed no significant alteration after SalA treatment (Fig. 4A, 4B), which suggested that SalA had no insulin secretagogue effect.

\section{Effects of SalA on mitochondrial function}

SalA increased ATP production in mitochondria. ATP production is the main activity of mitochondria. To explore whether SalA targets mitochondrial function, we investigated the effects of SalA on ATP production in both cultured cells and isolated mitochondria. After treatment with SalA in HepG2 cells and L6 myotubes, ATP production displayed significant dose-dependent increase from $10 \mathrm{~min}$ to $12 \mathrm{~h}$ with the strongest effect at $10^{-7} \mathrm{M}$ and $10^{-6} \mathrm{M}$ (Fig. 5A, 5B). In isolated mitochondria, SalA increased ATP production dose-dependently in hepatic mitochondria, while showed no significant effect in skeletal muscle mitochondria (Fig. 5C, 5D). Altogether, SalA increased ATP production in mitochondria.

SalA decreased mitochondrial membrane potential. Monitoring mitochondrial membrane potential is used to assess mitochondrial function. A lower membrane potential can prevent free radical production. So, we investigated whether SalA works on mitochondrial membrane potential. Interestingly, our results showed that 30-min treatment of SalA dose-dependently reduced Rhodamine 123 in HepG2 cells, suggesting that SalA decreased mitochondrial membrane potential in hepatocytes (Fig. 6A, 6B). In isolated hepatic and skeletal muscle mitochondria, we also found that mitochondrial membrane potential was decreased after 10-min treatment of SalA (Fig. 6C, 6D). Collectively, SalA decreased mitochondrial membrane potential in hepatic and skeletal muscle mitochondria.

SalA improved mitochondrial respiratory functions. Respiratory control ratio is the single most useful general test of function in isolated mitochondria. High RCR indicates good function and lower RCR usually indicates dysfunction [27]. Our previous findings have demonstrated that SalA improved the mitochondrial function in high-fat diet-fed 


\section{Cellular Physiology Cell Physiol Biochem 2015;36:395-408 \\ \begin{tabular}{l|l|l} 
and Biochemistry & $\begin{array}{l}\text { DOI: 10.1159/000430258 } \\
\text { Published online: May 7, } 2015\end{array}$ & $\begin{array}{l}\text { O 2015 S. Karger AG, Basel } \\
\text { www.karger.com/cpb }\end{array}$ \\
\cline { 2 - 3 } &
\end{tabular} \\ Qiang et al:: Antidiabetic Effect of Salvianolic Acid A via Mitochondrial Regulation}

Table 1. Effects of SalA on mitochondrial respiratory properties in isolated hepatic mitochondria. RCR: State 3/State4; ADP/O: nmol ADP/nmol 0; State 3: nmol 0/min/mg prot; State 4: nmol O/ $\mathrm{min} / \mathrm{mg}$ prot; OPR: $\mathrm{nmol}$ ATP/min/mg prot; Complex I substrates: L-glutamate plus L-malate; Complex II substrate: succinate. Results are mean \pm S.E.M. $(n=6) .{ }^{*} P<0.05,{ }^{* *} P<0.01$ vs. vehicle group

\begin{tabular}{cccccc}
\hline \multirow{2}{*}{ Respiratory activities } & \multicolumn{5}{c}{ Complex I substrate } \\
& RCR & ADP/O & State 3 & State 4 & OPR \\
\hline Vehicle & $3.54 \pm 0.05$ & $2.04 \pm 0.04$ & $56.17 \pm 1.91$ & $16.17 \pm 0.64$ & $115.57 \pm 5.78$ \\
SalA $10^{-9} \mathrm{M}$ & $3.65 \pm 0.16$ & $2.17 \pm 0.10$ & $61.33 \pm 2.67$ & $16.93 \pm 0.93$ & $133.66 \pm 10.82$ \\
SalA $10^{-8} \mathrm{M}$ & $3.87 \pm 0.10^{*}$ & $2.13 \pm 0.06$ & $62.40 \pm 2.56$ & $15.91 \pm 0.72$ & $117.78 \pm 6.70$ \\
SalA $10^{-7} \mathrm{M}$ & $3.55 \pm 0.11$ & $2.17 \pm 0.04$ & $57.64 \pm 2.05$ & $15.87 \pm 0.80$ & $123.06 \pm 4.97$ \\
SalA $10^{-6} \mathrm{M}$ & $3.55 \pm 0.10$ & $2.22 \pm 0.06^{*}$ & $56.00 \pm 2.67$ & $16.16 \pm 0.85$ & $123.60 \pm 5.06$ \\
\hline
\end{tabular}

Table 2. Effects of SalA on mitochondrial respiratory properties in isolated skeletal muscle mitochondria. RCR: State 3/State4; ADP/O: nmol ADP/nmol 0; State 3: nmol 0/min/mg prot; State $4: \mathrm{nmol} \mathrm{O} / \mathrm{min} / \mathrm{mg}$ prot; OPR: $\mathrm{nmol} \mathrm{ATP} / \mathrm{min} / \mathrm{mg}$ prot; Complex I substrates: L-glutamate plus L-malate. Results are mean \pm S.E.M. $(n=6) .{ }^{*} P<0.05,{ }^{* *} P<0.01$ vs. vehicle group

\begin{tabular}{cccccc}
\hline \multirow{2}{*}{ Respiratory activities } & \multicolumn{5}{c}{ Complex I substrate } \\
& RCR & ADP $/ 0$ & State 3 & State 4 & OPR \\
\hline Vehicle & $4.60 \pm 0.37$ & $2.23 \pm 0.10$ & $219.44 \pm 14.23$ & $42.55 \pm 1.28$ & $458.22 \pm 55.41$ \\
SalA 10-9 M & $6.07 \pm 0.29^{* *}$ & $2.59 \pm 0.09^{*}$ & $219.69 \pm 14.88$ & $40.22 \pm 2.29$ & $537.24 \pm 48.67$ \\
SalA 10-8 M & $5.77 \pm 0.23^{*}$ & $2.55 \pm 0.08^{*}$ & $220.63 \pm 16.53$ & $40.84 \pm 2.20$ & $553.34 \pm 63.70$ \\
SalA 10-7 M & $5.75 \pm 0.31^{*}$ & $2.36 \pm 0.10$ & $215.00 \pm 11.95$ & $39.19 \pm 2.81$ & $492.86 \pm 48.77$ \\
SalA 10-6 M & $5.69 \pm 0.46^{*}$ & $2.34 \pm 0.09$ & $207.50 \pm 12.99$ & $40.00 \pm 2.34$ & $470.01 \pm 39.83$ \\
\hline
\end{tabular}

and STZ-induced type 2 diabetic rats [28]. Here, to further verify the effect of SalA on the mitochondrial respiratory function, hepatic and skeletal muscle mitochondria in normal rats were isolated and treated with SalA. In both hepatic and skeletal muscle mitochondria, SalA increased RCR, ADP/O, and OPR under complex I substrates stimulation (Table 1 and Table 2). These results suggested that SalA may improve mitochondrial function.

SalA activated phosphorylation of AMPK via CaMKKB/AMPK signaling pathway. AMPK is a metabolic master switch regulating mitochondria, glucose uptake and fatty acid oxidation [29]. To explore if AMPK is involved in the antidiabetic mechanisms of SalA, we detected AMPK expression in HepG2 and differentiated L6 myotubes under SalA treatment. Our results showed that AMPK was phosphorylated in a dose- and time-dependent manner under SalA stimulation (Fig. 7A-F).

LKB1 and CaMKK $\beta$ are two important upstream kinases for AMPK, while upstream kinase of the major AMPK in L6 cells is LKB1. To identify the upstream kinase of AMPK, we examined the effect of SalA in HeLa cells with only expression of CaMKK $\beta$ as AMPK upstream kinase and deficiency in LKB1. We found that SalA also activated phosphorylation of AMPK in HeLa cells, suggesting that LKB1 might not be the upstream kinase of AMPK (Fig. 7G). Pretreatment with specific CaMKK $\beta$ inhibitor STO-609 or specific AMPK inhibitor compound $\mathrm{C}$ significantly inhibited phosphorylation of AMPK, which wasn't activated by cotreatment with SalA (Fig. 7H). Collectively, these results demonstrated that SalA activates AMPK phosphorylation probably through CaMKK $\beta /$ AMPK signaling pathway, independent of LKB1.

SalA did not activate phosphorylation of Akt. To test whether SalA modulates glucose metabolism via PI3K/Akt pathway known to play a major regulatory role in insulin pathway, we detected the Akt expression under SalA treatment. Our results showed that SalA did not phosphorylate Akt in both HepG2 cells and L6 myotubes (Fig. 8A-D). It suggested that SalA exhibited antidiabetic effect not through PI3K/Akt signaling pathway, consistent with the absent insulin-secretagogue effect of SalA. 


\section{Cellular Physiology Cell Physiol Biochem 2015;36:395-408 \begin{tabular}{l|l} 
and Biochemistry $\begin{array}{l}\text { DOI.1159/000430258 } \\
\text { Published online: May 7, } 2015\end{array}$ & $\begin{array}{l}\text { O 2015 S. Karger AG, Basel } \\
\text { www.karger.com/cpb }\end{array}$ \\
\cline { 2 - 3 }
\end{tabular}

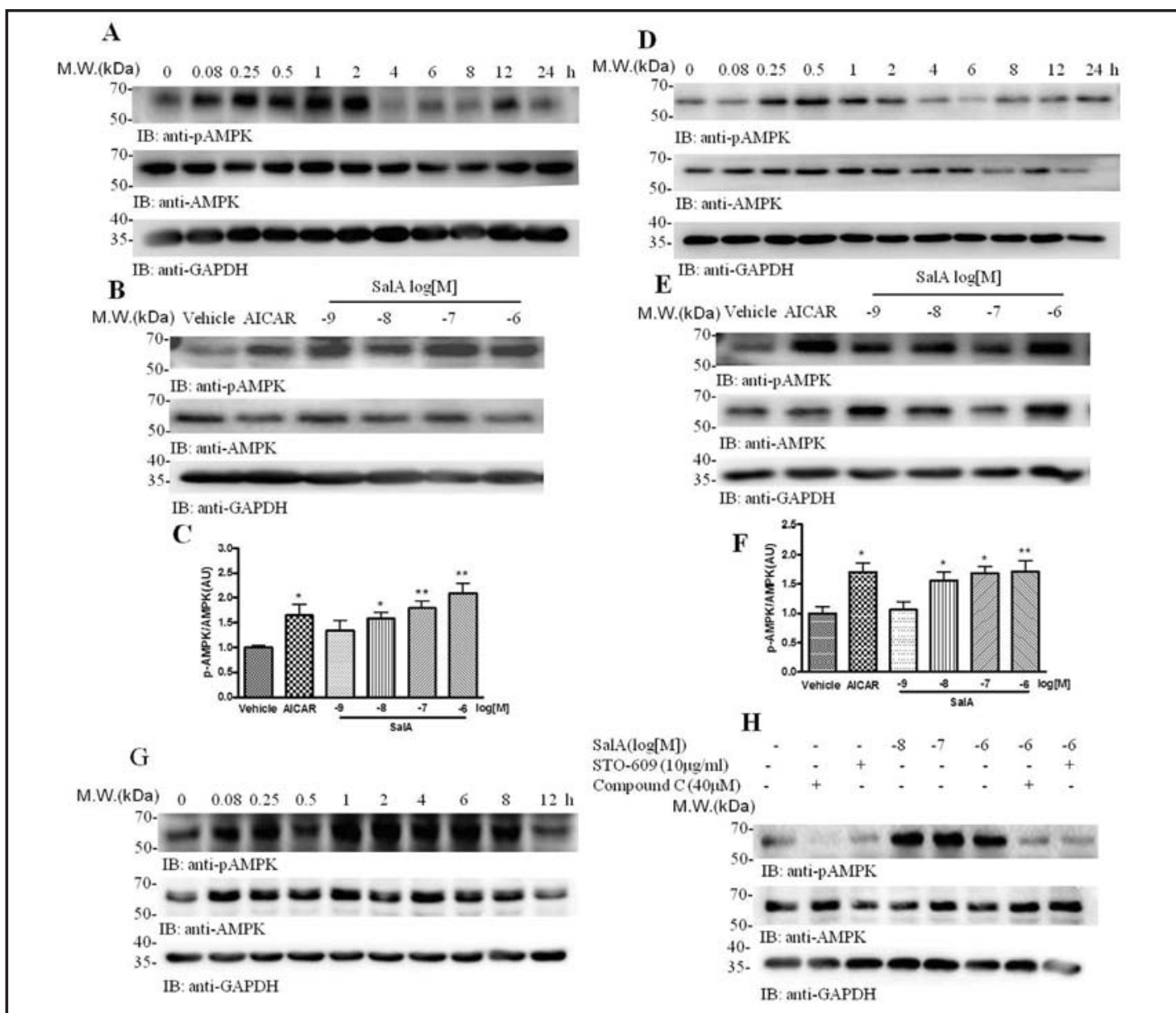

Fig. 7. SalA activated AMPK phosphorylation via CaMKK $\beta / A M P K$ signaling pathway. After treatment with SalA $\left(10^{-6} \mathrm{M}\right)$ from 5 min to $24 \mathrm{~h}$, phosphorylations of AMPK in (A) HepG2 cells and (D) L6 myotubes at time-response effect were determined by western blot. Representative blots for dose-response effect of SalA $\left(10^{-9}-10^{-6} \mathrm{M}\right)$ in (B) HepG2 cells at $1 \mathrm{~h}$ and (E) L6 myotubes at $30 \mathrm{~min}$. Quantification of the ratio of phospho-AMPK to total AMPK in (C) HepG2 cells and (F) L6 myotubes. (G) After HeLa cells were treated with SalA $\left(10^{-6} \mathrm{M}\right)$ from $5 \mathrm{~min}$ to $24 \mathrm{~h}$, phosphorylation of AMPK at time-response effect were detected by western blot. (H) After pretreatment with AMPK inhibitor Compound C $(40 \mu \mathrm{M})$ or CaMKK $\beta$ inhibitor STO-609 $(10 \mu \mathrm{g} /$ $\mathrm{ml}$ ) for $30 \mathrm{~min}$ at $37^{\circ} \mathrm{C}$, HeLa cells were treated with SalA $\left(10^{-8}-10^{-6} \mathrm{M}\right)$ for $2 \mathrm{~h}$ with or without Compound C or ST0-609 treatment, phosphorylation of AMPK were detected by western blot. Results are represented as mean \pm S.E.M. from three separate experiments. ${ }^{*} P<0.05$, ${ }^{* *} P<0.01$ vs. vehicle group.

\section{Discussion}

In this report, we have demonstrated that SalA, a small-molecular-weight natural product from Salvia Miltiorrhiza Bunge, exhibits antidiabetic effect in both in vivo and in vitro. SalA lowered fasting and fed blood glucose in both type 1 diabetic mouse and type 2 diabetic rat models, as well as increased glucose consumption in hepatocytes and enhanced glucose uptake in myotubes. Further findings supported that the antidiabetic effect of SalA may be attributed to significant improvement of mitochondrial function via AMPK signaling pathway.

The majority of ATP is generated by proton gradient in the mitochondria through oxidative phosphorylation during glucose metabolism. ATP is requisite to maintain the cellular processes and adequate ATP supplements by energy metabolisms are crucial for the treatment and prevention of many diseases [30]. It is well known that type 2 diabetes is not 


\section{Cellular Physiology Cell Physiol Biochem 2015;36:395-408

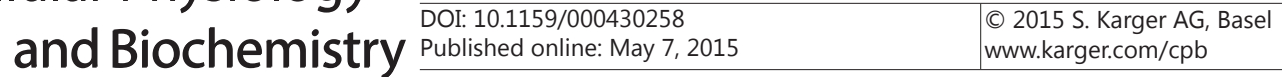

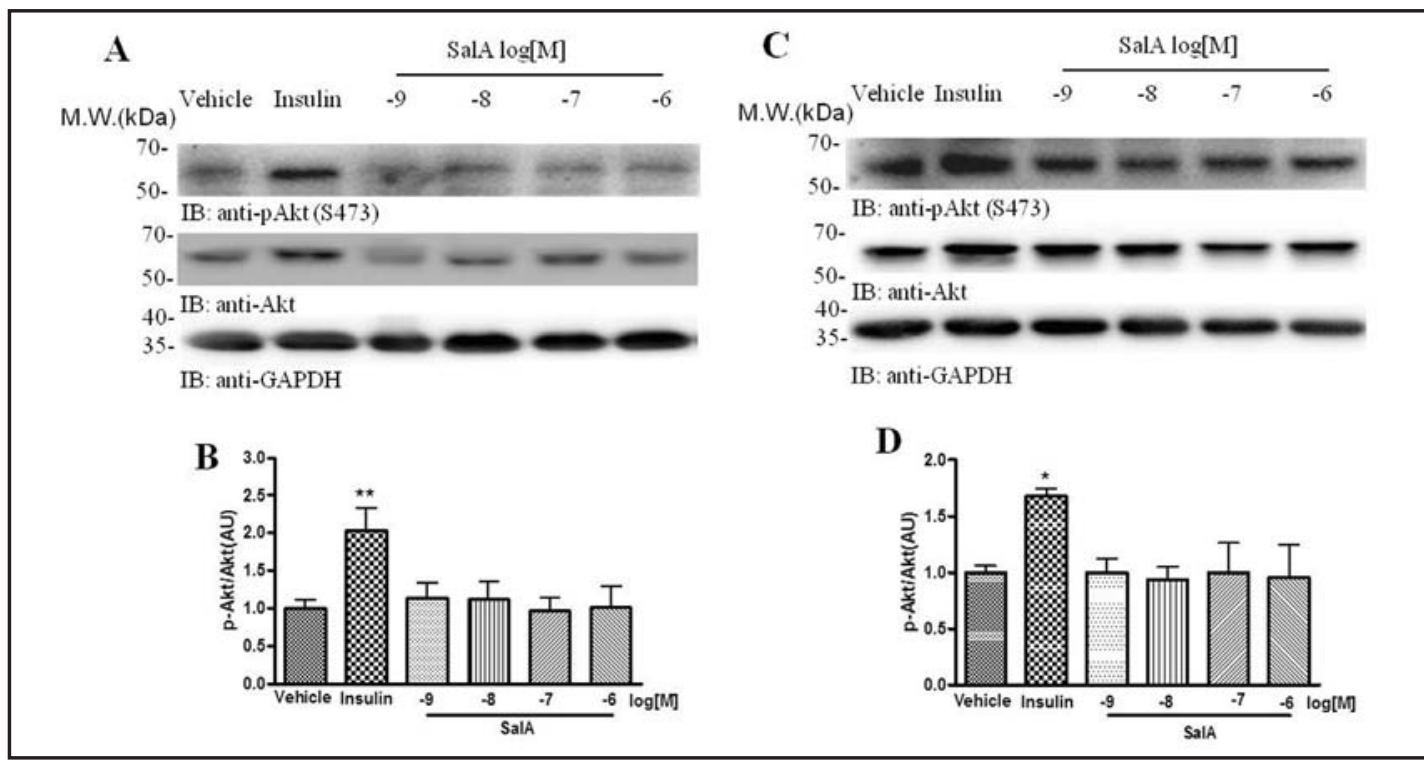

Fig. 8. SalA did not phosphorylate Akt. After treatment with different concentrations of SalA $\left(10^{-9}-10^{-6} \mathrm{M}\right)$ for $30 \mathrm{~min}$, phosphorylation of Akt was detected by western blot analysis. Representative blots in (A) HepG2 cells and (C) L6 myotubes. Quantification of the ratio of phospho-Akt to total Akt in (B) HepG2 cells and (D) L6 myotubes. Results are represented as mean \pm S.E.M. from three separate experiments. ${ }^{*} P<0.05,{ }^{* *} P<0.01$ vs. vehicle group.

merely a disease of insulin insensitivity or lack of insulin release but a global dysfunction of mitochondrial energy system [31]. Therefore, treatment of diabetes should focus on the improvement of mitochondrial function [31]. Our previous studies demonstrated that SalA promoted ATP production in myocardial, endothelial and smooth muscle cell (data not shown). In the current study, we found that SalA increased ATP production in both hepatic HepG2 and skeletal muscle L6 myotubes, consistent with improving the mitochondrial respiratory function of liver and skeletal muscle. Taken together, these data indicated that SalA exhibited the antidiabetic effect through targeting mitochondria.

A lower membrane potential can prevent free radical production. $\Delta \Psi \mathrm{m}$ is directly related to reactive oxygen species (ROS) production: at higher potentials starting at $\Delta \Psi \mathrm{m}>140 \mathrm{mV}$, ROS production increases exponentially $[32,33]$. In diabetic patients, hyperglycemia can induce mitochondrial superoxide production, not only contributing to the development of complications, but also being involved during post-hyperglycemia periods of normal glycaemia [34]. Therefore, maintenance of lower $\Delta \Psi \mathrm{m}$, avoiding ROS generation, and providing full capability to produce ATP would be beneficial for diabetes treatment. In our study, SalA promoted the intracellular ATP production, while decreased mitochondrial membrane potential without any cytotoxicity effect on skeletal muscle L6 and hepatic HepG2 cells (data not shown). In addition, SalA increased ADP/O in both skeletal muscle and hepatic mitochondria in normal rats with robust improvement of RCR in skeletal muscle mitochondria. Those results are consistent with our previous findings in high-fat diet-fed and STZ-induced type 2 diabetic rats $[3,16,28]$. More interestingly, the effect of SalA is different from the common antidiabetic agents, as both metformin and TZDs inhibit complex I activity and cell respiration [35-37]. Recent studies have shown that decreasing mitochondrial membrane potential might be an important target for development of antidiabetic agents [38]. In our study, SalA decreased mitochondrial membrane potential level and increased ATP production. These unique functions of SalA make it appealing for diabetes treatment.

AMPK, a serine/threonine protein kinase, acts as a metabolic master switch regulating cellular metabolism and energy balance [39]. Abnormal AMPK activity is closely associated with diabetes. Therefore, AMPK has been recognized as a promising therapeutic target for type 2 diabetes $[38,40]$. Some antidiabetic agents, such as metformin, rosiglitazone, and 


\section{Cellular Physiology Cell Physiol Biochem 2015;36:395-408

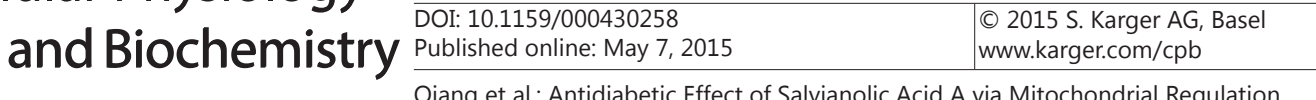

natural products like berberine and resveratrol, have been demonstrated to activate AMPK signaling pathway [37, 41-43]. We found that AMPK in HepG2 cells and L6 myotubes was phosphorylated by SalA in dose- and time-dependent manner. It has been known that AMPK activity is switched on in several catabolic pathways for ATP generation such as glucose uptake, consumption, and glycolysis [30,44]. So AMPK is involved in ATP production and maintenance of glucose homeostasis. Thus, SalA activates phosphorylation of AMPK, which triggers intracellular metabolic changes, including increasing glucose uptake in skeletal muscle and decreasing glucose production in liver, and eventually leads to glucose-lowering.

It is well known that LKB1 kinase mediates the therapeutic effect of metformin [45]. Apart from LKB1, two other kinases, CaMKK $\beta$ and TGF- $\beta$-activated kinase 1 (Tak1), have also been identified as AMPK phosphorylating kinase. Tak1 regulates AMPK activity by phosphorylation on Thr172 [46]. CaMKK $\beta$ phosphorylates AMPK responding to the elevated intracellular $\mathrm{Ca}^{2+}$ concentrations, independent of any changes in cellular AMP/ATP ratio [47]. We found that SalA was able to phosphorylate AMPK in HeLa cell with deficiency in LKB1, which suggested that SalA activated cellular AMPK activity independent of LKB1. Furthermore, CaMKK $\beta$ inhibitor STO-609 blocked AMPK phosphorylation in HeLa cells, suggesting that phosphorylation of AMPK by SalA might be through CaMKK $\beta$ pathway, not LKB1, as was different from metformin [45].

Increasing glucose consumption and glucose uptake in periphery tissues (liver and skeletal muscle) contributes to lowering postprandial glucose. It is well known that in addition to fasting hyperglycemia, postprandial hyperglycemia is also one of the earliest abnormalities of glucose homeostasis associated with type 2 diabetes and is markedly exaggerated with fasting hyperglycemia [48]. SalA lowered fasting blood glucose mildly in type 1 diabetic mice and significantly in type 2 diabetic rats. Furthermore, SalA markedly lowered fed blood glucose in both diabetic animal models. Particularly, we did not find the significant toxicity in long-term toxicity test, suggesting that SalA can be used with greater safety (data not shown). Hence, lowering fasting and fed blood glucose with remarkable safety makes SalA attractive in the development of antidiabetic drug.

Taken together, SalA exhibits the antidiabetic effect through improving mitochondrial function and switching on AMPK via CaMKK $\beta$ /AMPK signaling pathway. Interestingly, its activities of decreasing mitochondrial membrane potential and increasing ATP production make SalA unique and appealing in antidiabetic effect. These findings indicate that SalA may serve as a novel and potential therapeutic option for diabetes treatment.

\section{Acknowledgments}

This research was supported by grants from the National Science and Technology Major Project (Number: 2009ZX09102-123, 2013ZX09508104) and National Natural Science Foundation of China (81470159).

\section{Disclosure Statement}

The authors declared no competing interests.

\section{References}

1 The effect of intensive treatment of diabetes on the development and progression of long-term complications in insulin-dependent diabetes mellitus. The Diabetes Control and Complications Trial Research Group. N Engl J Med 1993;329:977-986.

2 Intensive blood-glucose control with sulphonylureas or insulin compared with conventional treatment and risk of complications in patients with type 2 diabetes (UKPDS 33). UK Prospective Diabetes Study (UKPDS) Group. Lancet 1998;352:837-853. 


\section{Cellular Physiology Cell Physiol Biochem 2015;36:395-408

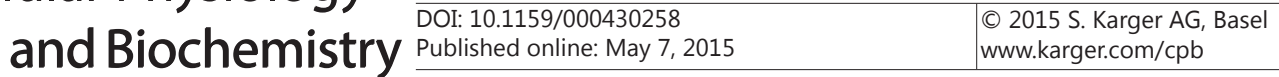 \\ Qiang et al:: Antidiabetic Effect of Salvianolic Acid A via Mitochondrial Regulation}

3 Yu X, Zhang L, Yang X, Huang H, Huang Z, Shi L, Zhang H, Du G: Salvianolic acid A protects the peripheral nerve function in diabetic rats through regulation of the AMPK-PGC1alpha-Sirt3 axis. Molecules 2012;17:11216-11228.

4 Inzucchi SE: Clinical practice. Management of hyperglycemia in the hospital setting. N Engl J Med 2006;355:1903-1911.

5 Jung M, Park M, Lee HC, Kang YH, Kang ES, Kim SK: Antidiabetic agents from medicinal plants. Curr Med Chem 2006;13:1203-1218.

6 Mohamed Bnouham AZ, Hassane Mekhfi AT, Legssyer A: Medicinal plants with potential antidiabetic activity - A review of ten years of herbal medicine research (1990-2000). Int J Diabetes \& Metabolism 2006;14:1-25.

7 Lian-Niang L, Rui T, Wei-Ming C: Salvianolic Acid A, a New Depside from Roots of Salvia miltiorrhiza. Planta Med 1984;50:227-228.

8 Huang YS, Zhang JT: Antioxidative effect of three water-soluble components isolated from Salvia miltiorrhiza in vitro. Yao Xue Xue Bao 1992;27:96-100.

9 Yu WG, Xu LN: Effect of acetylsalvianolic acid A on platelet function. Yao Xue Xue Bao 1994;29:412-416.

10 Du G, Zhang J: Protective effects of salvianolic acid A against impairment of memory induced by cerebral ischemia-reperfusion in mice. Chin Med J (Engl) 1997;110:65-68.

11 Du GH, Qiu Y, Zhang JT: Protective effect of salvianolic acid a on ischemia-reperfusion induced injury in isolated rat heart. Yao Xue Xue Bao 1995;30:731-735.

12 Hu YY, Liu P, Liu C, Xu LM, Liu CH, Zhu DY, Huang MF: Actions of salvianolic acid A on CCl4-poisoned liver injury and fibrosis in rats. Zhongguo Yao Li Xue Bao 1997;18:478-480.

13 Wang P, Xu S, Li W, Wang F, Yang Z, Jiang L, Wang Q, Huang M, Zhou P: Salvianolic acid B inhibited PPARgamma expression and attenuated weight gain in mice with high-fat diet-induced obesity. Cell Physiol Biochem 2014;34:288-298.

14 Wang SB, Yang XY, Tian S, Yang HG, Du GH: Effect of salvianolic acid A on vascular reactivity of streptozotocin-induced diabetic rats. Life Sci 2009;85:499-504.

15 Yang XY, Qiang GF, Zhang L, Zhu XM, Wang SB, Sun L, Yang HG, Du GH: Salvianolic acid A protects against vascular endothelial dysfunction in high-fat diet fed and streptozotocin-induced diabetic rats. J Asian Nat Prod Res 2011;13:884-894.

16 Yang XY, Sun L, Xu P, Gong LL, Qiang GF, Zhang L, Du GH: Effects of salvianolic scid A on plantar microcirculation and peripheral nerve function in diabetic rats. European journal of pharmacology 2011;665:40-46.

17 Bouvet C, Peeters W, Moreau S, DeBlois D, Moreau P: A new rat model of diabetic macrovascular complication. Cardiovasc Res 2007;73:504-511.

18 Sachidanandam K, Hutchinson JR, Elgebaly MM, Mezzetti EM, Wang MH, Ergul A: Differential effects of diet-induced dyslipidemia and hyperglycemia on mesenteric resistance artery structure and function in type 2 diabetes. J Pharmacol Exp Ther 2009;328:123-130.

19 Srinivasan K, Viswanad B, Asrat L, Kaul CL, Ramarao P: Combination of high-fat diet-fed and low-dose streptozotocin-treated rat: a model for type 2 diabetes and pharmacological screening. Pharmacol Res 2005;52:313-320.

20 Zhang L, Hu J, Du G: Establishment of a cell-based assay to screen insulin-like hypoglycemic drugs. Drug Discov Ther 2008;2:229-233.

21 Lakshmanan J, Elmendorf JS, Ozcan S: Analysis of insulin-stimulated glucose uptake in differentiated 3T3L1 adipocytes. Methods Mol Med 2003;83:97-103.

22 Pon LA, Schon EA: Mitochondria, 2nd Edition Amsterdam: Elisevier Inc, 2007:4-8.

23 Chance B, Williams GR: The respiratory chain and oxidative phosphorylation. Adv Enzymol Relat Subj Biochem 1956;17:65-134.

24 He XL, Wang YH, Gao M, Li XX, Zhang TT, Du GH: Baicalein protects rat brain mitochondria against chronic cerebral hypoperfusion-induced oxidative damage. Brain Res 2009;1249:212-221.

25 Baracca A, Sgarbi G, Solaini G, Lenaz G: Rhodamine 123 as a probe of mitochondrial membrane potential: evaluation of proton flux through F(0) during ATP synthesis. Biochim Biophys Acta 2003;1606:137-146.

26 Xu WW, Guan MP, Zheng ZJ, Gao F, Zeng YM, Qin Y, Xue YM: Exendin-4 alleviates high glucose-induced rat mesangial cell dysfunction through the AMPK pathway. Cell Physiol Biochem 2014;33:423-432.

27 Brand MD, Nicholls DG: Assessing mitochondrial dysfunction in cells. Biochem J 2009;435:297-312. 


\section{Cellular Physiology Cell Physiol Biochem 2015;36:395-408

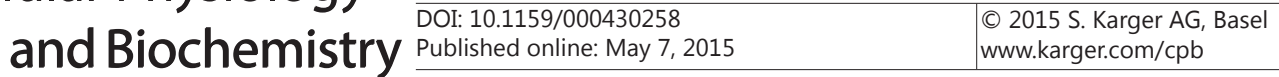 \\ Qiang et al:: Antidiabetic Effect of Salvianolic Acid A via Mitochondrial Regulation}

28 Qiang G, Yang X, Xuan Q Shi L, Zhang H, Chen B, Li X, Zu M, Zhou D, Guo J, Yang H, Zhang L, Du G: Salvianolic Acid a prevents the pathological progression of hepatic fibrosis in high-fat diet-fed and streptozotocininduced diabetic rats. Am J Chin Med 2014;42:1183-1198.

29 Wang XM, Song SS, Xiao H, Gao P, Li XJ, Si LY: Fibroblast growth factor 21 protects against high glucose induced cellular damage and dysfunction of endothelial nitric-oxide synthase in endothelial cells. Cell Physiol Biochem 2014;34:658-671.

30 Hwang JT, Kwon DY, Yoon SH: AMP-activated protein kinase: a potential target for the diseases prevention by natural occurring polyphenols. N Biotechnol 2009;26:17-22.

31 Lamson DW, Plaza SM: Mitochondrial factors in the pathogenesis of diabetes: a hypothesis for treatment. Altern Med Rev 2002;7:94-111.

32 Korshunov SS, Skulachev VP, Starkov AA: High protonic potential actuates a mechanism of production of reactive oxygen species in mitochondria. FEBS Lett 1997;416:15-18.

33 Liu SS: Cooperation of a "reactive oxygen cycle" with the Q cycle and the proton cycle in the respiratory chain--superoxide generating and cycling mechanisms in mitochondria. J Bioenerg Biomembr 1999;31:367-376.

34 Brownlee M: Biochemistry and molecular cell biology of diabetic complications. Nature 2001;414:813-820.

35 El-Mir M, Nogueira V, Fontaine E, Avéret N, Rigoulet M, Leverve X: Dimethylbiguanide inhibits cell respiration via an indirect effect targeted on the respiratory chain complex I. J Biol Chem 2000;275:223228.

36 Brunmair B, Staniek K, Gras F, Scharf N, Althaym A, Clara R, Roden M, Gnaiger E, Nohl H, Waldhausl W, Furnsinn C: Thiazolidinediones, like metformin, inhibit respiratory complex I: a common mechanism contributing to their antidiabetic actions? Diabetes 2004;53:1052-1059.

37 Turner N, Li JY, Gosby A, To SW, Cheng Z, Miyoshi H, Taketo MM, Cooney GJ, Kraegen EW, James DE, Hu LH, Li J, Ye JM: Berberine and its more biologically available derivative, dihydroberberine, inhibit mitochondrial respiratory complex I: a mechanism for the action of berberine to activate AMP-activated protein kinase and improve insulin action. Diabetes 2008;57:1414-1418.

38 Qiu BY, Turner N, Li YY, Gu M, Huang MW, Wu F, Pang T, Nan FJ, Ye JM, Li JY, Li J: High-throughput assay for modulators of mitochondrial membrane potential identifies a novel compound with beneficial effects on db/db mice. Diabetes 2010;59:256-265.

39 Papadimitriou A, Peixoto EB, Silva KC, Lopes de Faria JM, Lopes de Faria JB: Inactivation of AMPK mediates high phosphate-induced extracellular matrix accumulation via NOX4/TGFss-1 signaling in human mesangial cells. Cell Physiol Biochem 2014;34:1260-1272.

40 Musi N, Goodyear LJ: Insulin resistance and improvements in signal transduction. Endocrine 2006;29:7380.

41 Zhou G, Myers R, Li Y, Chen Y, Shen X, Fenyk-Melody J, Wu M, Ventre J, Doebber T, Fujii N, Musi N, Hirshman MF, Goodyear LJ, Moller DE: Role of AMP-activated protein kinase in mechanism of metformin action. J Clin Invest 2001;108:1167-1174.

42 Ye JM, Dzamko N, Hoy AJ, Iglesias MA, Kemp B, Kraegen E: Rosiglitazone treatment enhances acute AMPactivated protein kinase-mediated muscle and adipose tissue glucose uptake in high-fat-fed rats. Diabetes 2006;55:2797-2804.

43 Shin SM, Cho IJ, Kim SG: Resveratrol protects mitochondria against oxidative stress through AMP-activated protein kinase-mediated glycogen synthase kinase-3beta inhibition downstream of poly(ADP-ribose) polymerase-LKB1 pathway. Mol Pharmacol 2009;76:884-895.

44 Hardie DG: The AMP-activated protein kinase pathway--new players upstream and downstream. J Cell Sci 2004;117:5479-5487.

45 Shaw RJ, Lamia KA, Vasquez D, Koo SH, Bardeesy N, Depinho RA, Montminy M, Cantley LC: The kinase LKB1 mediates glucose homeostasis in liver and therapeutic effects of metformin. Science 2005;310:1642-1646.

46 Russo GL, Russo M, Ungaro P: AMP-activated protein kinase: a target for old drugs against diabetes and cancer. Biochem Pharmacol 2013;86:339-350.

47 Woods A, Dickerson K, Heath R, Hong SP, Momcilovic M, Johnstone SR, Carlson M, Carling D: Ca ${ }^{2+}$ / calmodulin-dependent protein kinase kinase-beta acts upstream of AMP-activated protein kinase in mammalian cells. Cell Metab 2005;2:21-33.

48 Postprandial blood glucose. American Diabetes Association. Diabetes care 2001;24:775-778. 